Int. J. Dev. Biol. 61: 53-63 (2017)

doi: $10.1387 / \mathrm{ijdb} .160321 \mathrm{es}$

\title{
The pioneer factor Smed-gata456-1 is required for gut cell differentiation and maintenance in planarians
}

\author{
ALEJANDRO GONZÁLEZ-SASTRE, NÍDIA DE SOUSA, TERESA ADELL and EMILI SALÓ* \\ Departament de Genètica, Microbiologia i Estadística, Facultat de Biologia, Universitat de Barcelona and Institut de \\ Biomedicina de la Universitat de Barcelona (IBUB), Universitat de Barcelona, Barcelona, Catalunya, Spain
}

\begin{abstract}
How adult stem cells differentiate into different cell types remains one of the most intriguing questions in regenerative medicine. Pioneer factors are transcription factors that can bind to and open chromatin, and are among the first elements involved in cell differentiation. We used the freshwater planarian Schmidtea mediterranea as a model system to study the role of the gata456 family of pioneer factors in gut cell differentiation during both regeneration and maintenance of the digestive system. Our findings reveal the presence of two members of the gata456 family in the Schmidtea mediterranea genome; Smed-gata456-1 and Smed-gata456-2. Our results show that Smed-gata456-1 is the only ortholog with a gut cell-related function. Smed-gata456-1 is essential for the differentiation of precursors into intestinal cells and for the survival of these differentiated cells, indicating a key role in gut regeneration and maintenance. Furthermore, tissues other than the gut appear normal following Smed-gata456-1 RNA interference (RNAi), indicating a gut-specific function. Importantly, different neoblast subtypes are unaffected by Smed-gata4561(RNAi), suggesting that 1) Smed-gata456-1 is involved in the differentiation and maintenance, but not in the early determination, of gut cells; and 2) that the stem cell compartment is not dependent on a functional gut.
\end{abstract}

KEY WORDS: gut, gata456, planarian, regeneration, differentiation

\section{Introduction}

One of the most intriguing aspects of regenerative medicine is the ability of adult stem cells to differentiate into multiple cell types. Transcription factors, which drive transcriptional regulation in the cell, play crucial roles in determination and differentiation processes. Pioneer factors, a specific type of transcription factor, can bind to condensed chromatin, thus facilitating the binding of other transcription factors. Pioneer factors are often among the first elements to participate in the induction of determination and differentiation processes (rev. in Zaret and Carroll, 2011). Specifically, the gata456 subfamily of pioneer factors has a conserved role in endoderm determination and gut regionalization, and is active during both embryonic development (Fukushige et al., 1998; Reiter et al., 2001) and adulthood (Beuling et al., 2012; Okumura et al., 2016).

To better understand stem cell determination and differentiation, we investigated the role of gata 456 factors in the determination and differentiation of intestinal cells, which have a high rate of renewal, using the highly regenerative freshwater planarian Schmidtea mediterranea as a model species (Saló, 2006). Planarians can regenerate any lost body part and continuously renew all tissues during homeostasis, altering body size in accordance with nutrient availability. This continuous cell turnover during planarian regeneration and homeostasis is sustained by an abundant population of adult pluripotent stem cells called neoblasts (Baguñà, 2012), the proliferation, determination and differentiation of which is subject to complex and robust control. Planarians thus constitute an ideal system in which to study the processes of stem cell maintenance and specific fate determination, allowing us to analyse and compare gut cell specification and differentiation in two different scenarios, homeostasis and regeneration.

Our findings reveal the presence of two members of the gata456 family in the Schmidtea mediterranea genome; Smed-gata456-1 and Smed-gata456-2. Smed-gata456-1 is expressed in gut cells

Abbreviations used in this paper: RNAi, RNA interference.

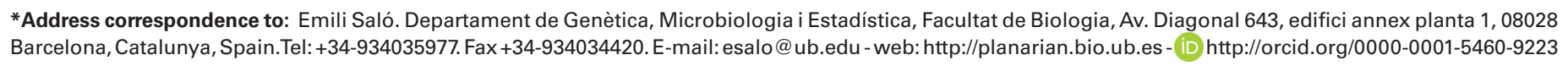

Supplementary Material (8 figures) for this paper is available at: http://dx.doi.org/10.1387/ijdb.160321es

Submitted: 9 September, 2016; Accepted: 12 December, 2016.

ISSN: Online 1696-3547, Print 0214-6282

(c) 2017 UPV/EHU Press

Printed in Spain 
and is essential for gut regeneration, while Smed-gata456-2 is involved in re-establishing mediolateral patterning during anterior regeneration. Our results show that Smed-gata456-1 is crucial for the regeneration, remodelling, and maintenance of gut tissue. In contrast to previous findings reported for Smed-nkx2.2 and Smedegfr-1, which are also implicated in gut regeneration (Forsthoefel et al., 2012; Barberán et al., 2016), we show that Smed-gata456-1 is not required for stem cell functionality, suggesting that 1) Smedgata456-1 is involved in the differentiation and maintenance, but not the early determination, of gut cells; and 2) the stem cell compartment is not dependent on a functional gut. Moreover, apart from the intestine, no other tissues appear to be affected in animals subjected to Smed-gata456-1 RNA interference (RNAi), suggesting an exclusive role of Smed-gata456-1 in the differentiation and maintenance of planarian gut cells.

\section{Results}

\section{Smed-gata456-1 is the planarian ortholog essential for gut regeneration}

By searching the transcriptomic database Planmine (Brandl et al., 2016) we identified in the transcriptome of $S$. mediterranea two gata456 orthologs, which we named Smed-gata456-1 (previously described as Smed-gata456in Wagner et al., 2011) and Smed-gata456-2 (S. Figs. 1 and 2). These genes correspond to the homologs of

Fig. 1. Gut regeneration and remodelling in regenerating tail fragments is impaired by Smed-gata4561(RNAi). (A) Live control and Smed-gata456-1 (RNAi) regenerating tail fragments at 8 days of regeneration. Red arrowhead indicates a lesion. (B) Quantification of the relative area of the blastema with respect to the total area of the regenerating tails. Error bars represent the standard error of the mean. Data were analyzed by Student's t-test; differences are considered significant at $P<0.05$. (C) Graph showing survival of regenerating tails of control $(n=45)$ and Smed-gata456-1 (RNAi) animals ( $n=48$ ). (D) Whole mount fluorescent in situ hybridization with the intestinal markerpk-1, prior to amputation. White dashed lines correspond to the plane of sectioning. (E) Whole mount fluorescent in situ hybridization for the intestinal marker pk-1 in a regenerating tail fragment, showing an absence of labelling in the new tissue of Smed-gata456-1(RNAi) animal. (F) Nuclear TOPRO-3 labelling in animals shown in E. White dashed lines in $E$ and $F$ indicates the estimated limit between the preexistent and the new tissue, since in tail fragments the new pharynx always appears in the anterior pre-existent tissue. (G) Fluorescent in situ hybridization for pk-1 (red) combined with immunohistochemistry using the muscular antibody 6 G10 (green) in serial transverse axial sections from the anterior tip (F1-1') to the posterior tip (F5-5') of the animal. Black dashed lines indicate the location of each transverse section. The anterior end is oriented to the left in (A), and in (E-F). The dorsal aspect is oriented to the top in (G). All images correspond to tail fragments after 8 days of regeneration. dr, days of regeneration. Scale bars: $500 \mu \mathrm{m}$ in $(A, D), 200 \mu \mathrm{m}$ in $(E-F), 100 \mu \mathrm{m}$ in (G). gata456 factors described in the planarian species Schmidtea polychroa (Spol-gata456Aand Spol-gata456B) (Martín-Durán and Romero, 2011). The same two homologs are found in four other planarian species, the transcriptomes of which are available in Planmine (see phylogenetic analysis in S. Fig. 1 and sequences in S. Fig. 2).

The expression of Smed-gata456-1 and Smed-gata456-2 was determined by whole mount in situ hybridization. In intact animals, Smed-gata456-1 was expressed in the gut and the surrounding parenchyma (S. Fig. 3A). The parenchyma associated expression disappeared 1 day after $X$ ray irradiation, demonstrating that
A
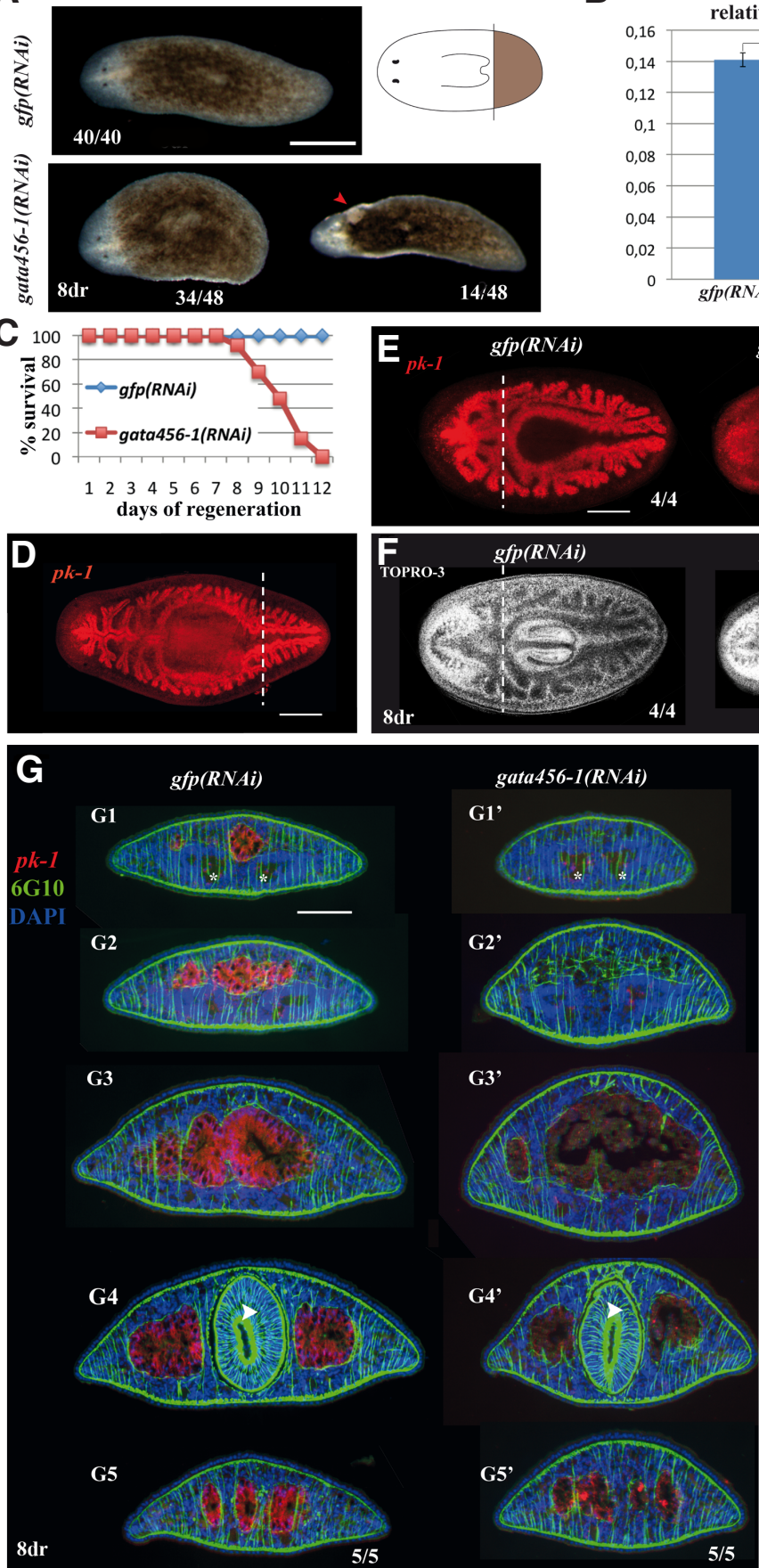

B
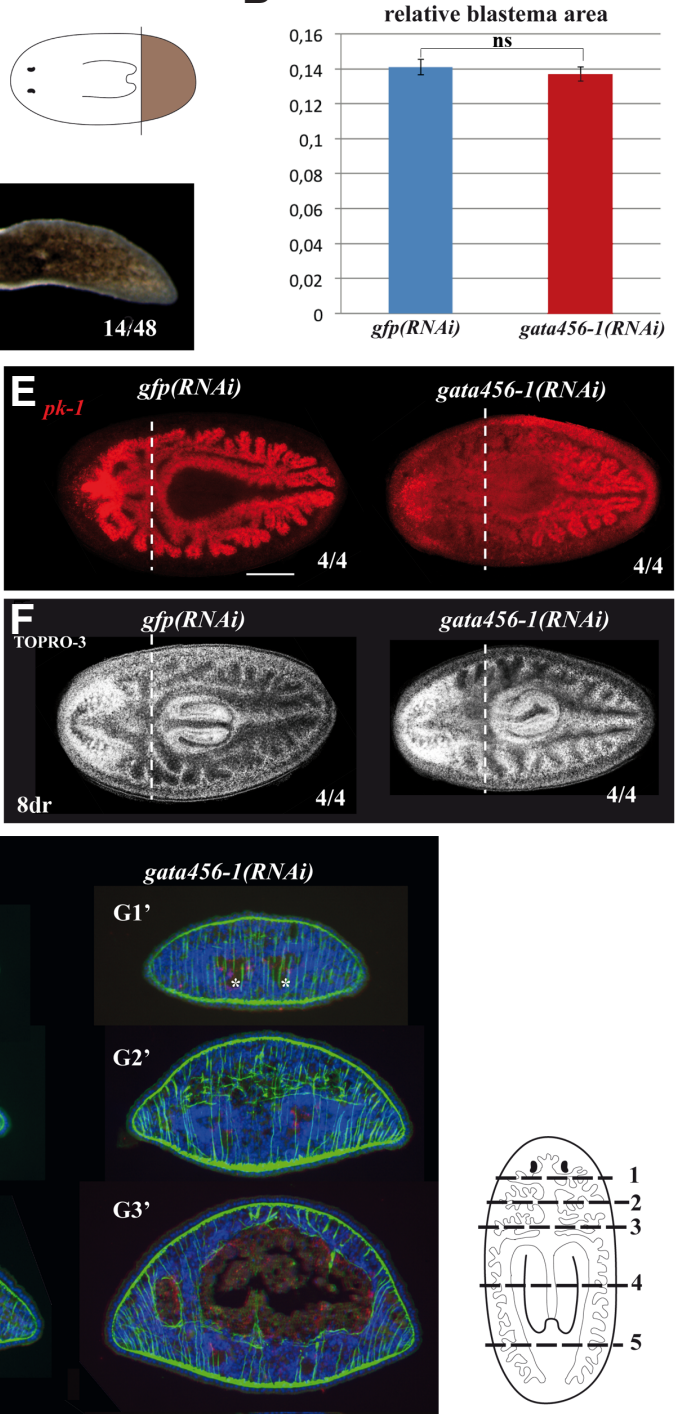

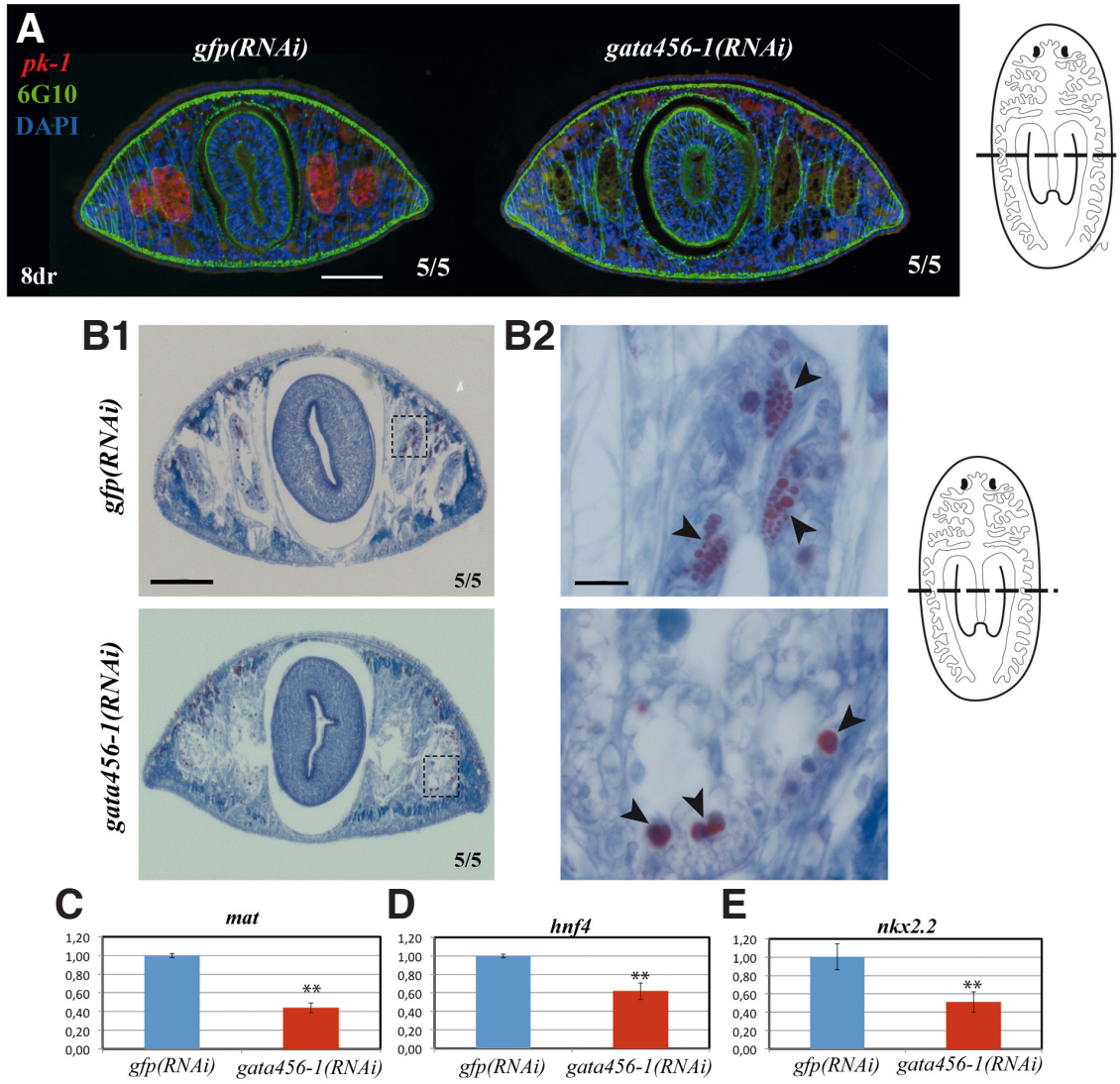

E

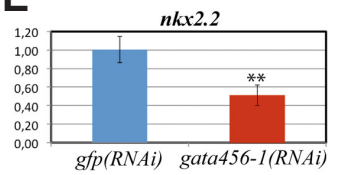

Fig. 2. Smed-gata456-1(RNAi) impairs gut remodelling during regeneration. (A) Fluorescent in situ hybridization for pk-1 (red) combined with immunohistochemistry with the 6G10 antibody (green) in transverse sections of the pharyngeal region from a bipolar regenerating trunk at 8 days of regeneration, showing an absence of labelling in the pre-existing gut in the Smed-gata456-1 (RNAi) animal. (B) Mallory staining of transverse sections. Magnified images in B2 correspond to dashed squares in B1. Arrowheads indicate secretory vesicles of goblet cells. (C-E) qRTPCR for the gut markers Smed-mat, Smed-hnf4, and Smed-nkx2.2. Error bars represent the standard error of the mean. Data were analyzed by Student's t-test. ${ }^{*} P<0.001$. The dorsal aspect is oriented to the top in $(A, B)$. Scale bars: $100 \mu \mathrm{m}$ in $(A, B 1)$; and $10 \mu \mathrm{m}$ in (B2). Dashed lines indicate the location of the transverse sections.
Smed-gata456-1 is expressed in neoblasts (S. Fig. 3A') (Wagner et al., 2011). At 2 days of regeneration, Smed-gata456-1 was highly expressed in the tips of the regenerating gut, in one anterior and two posterior clusters that corresponded to the anterior and the two posterior gut branches, respectively (S. Fig. 3B). Its homolog Spol-gata456A is also specifically present in embryonic gut cells (Martín-Durán and Romero, 2011). Smed-gata456-2was expressed in the parenchyma, especially around the anterior gut branch, the pharynx, and between the posterior gut branches (S. Fig. 3C), following an expression pattern similar to that observed for Spol-gata456b in S. polychroa (Martín-Durán and Romero, 2011).

To characterize their function, we knocked down Smed-gata456-1 and Smed-gata456-2 expression by injection of double-stranded RNA (dsRNA). Inhibition of Smed-gata456-1, confirmed by qRTPCR (S. Fig. 4A), resulted in normal early regeneration, with the formation of an anterior blastema and eyes in a regenerating tail (Fig. 1A). The relative size of the blastema at 8 days of regeneration shows no difference between Smed-gata456-1(RNAi) and the corresponding controls (Fig. 1B). However, beginning as early as day 7 of regeneration, small lesions gradually appeared in some animals, predominantly in the anterior region, followed by death of the animal the following day. All Smed-gata456-1(RNAi) animals died between 8 and 12 days of regeneration (Fig. 1C), i.e., 12 to 16 days after the last dsRNA injection. Regenerating trunk and head fragments showed a similar phenotype, although head fragments died earlier, after 5 to 7 days of regeneration (S. Fig. 4B-E). These results indicate that Smed-gata456-1(RNAi) does not interfere with early regeneration processes but is necessary for survival in later stages.
To examine the possible role of Smed-gata456-1 in the gut, we analysed the intestine in regenerating tail fragments in order to clearly differentiate de novo gut regeneration from remodelling of the pre-existing gut. Whole mount fluorescent in situ hybridization with the intestinal marker Smed-pk-1 (Fraguas et al., 2014) allow to visualize the planarian gut, which is composed of one anterior and two posterior gut branches that fuse in the region anterior to the pharynx (Fig. 1D, Forsthoefel et al., 2011). Analysis of pk-1 expression revealed that Smed-gata456-1(RNAi) animals are unable to regenerate the single anterior branch (Fig. 1E), although nuclear TOPRO-3 staining revealed apparently normal anterior regeneration (Fig. 1F). Moreover, pk-1 expression was absent in the central region of the animal, indicating that the two pre-existing gut branches failed to properly remodel and maintain their structure (Fig. 1E). Analysis of $p k-1$ in transverse sections, combined with 6G10 immunohistochemistry to label muscle fibres (Ross et al., 2015) and delimit the muscular intestinal plexus, also revealed an absence of gut labelling in the sections corresponding to the newly regenerated anterior portion of the animal (Fig. 1G1'-1G2'), and a faint, non-structured signal in the pre-existing posterior tip (Fig. 1G5'). Examination of the muscle fibres surrounding the gut suggested that, although the pre-existing posterior gut branches are remodelled to form the single anterior gut branch in the prepharyngeal region (Fig. 1G3'), this anterior branch cannot elongate through the anterior tip of the animal (Fig. 1 E,G'). Nuclear DAPI staining revealed the depletion of intestinal nuclei after Smedgata456-1(RNAi) (S. Fig. 5). Taken together, these results indicate that gut regeneration is blocked and gut remodelling impaired in Smed-gata456-1(RNAi) animals. 
Inhibition of Smed-gata456-2 resulted in aberrant regeneration of the anterior region of the animal. These animals regenerated two fused cephalic ganglia in the midline with a single cyclopic eye (S. Fig. 6 A-D). These defects in anterior regeneration were not due to alterations in early proliferation, which was normal in the anterior postblastema after both 6 and 48 hours of regeneration (S. Fig. 6E). Whole mount fluorescent in situ hybridization with the intestinal marker pk-1 revealed both anterior (S. Fig. 6F) and posterior (S. Fig. 6G) gut regeneration, although the length of the anterior gut branch in relation to the prepharyngeal region was slightly shorter than in controls (S. Fig. 6H).

In summary, planarians possess two Smed-gata456 orthologs. Only Smed-gata456-1 is expressed in gut cells, and plays an essential role in gut regeneration and remodelling, while Smedgata456-2 is implicated in anterior mediolateral patterning.

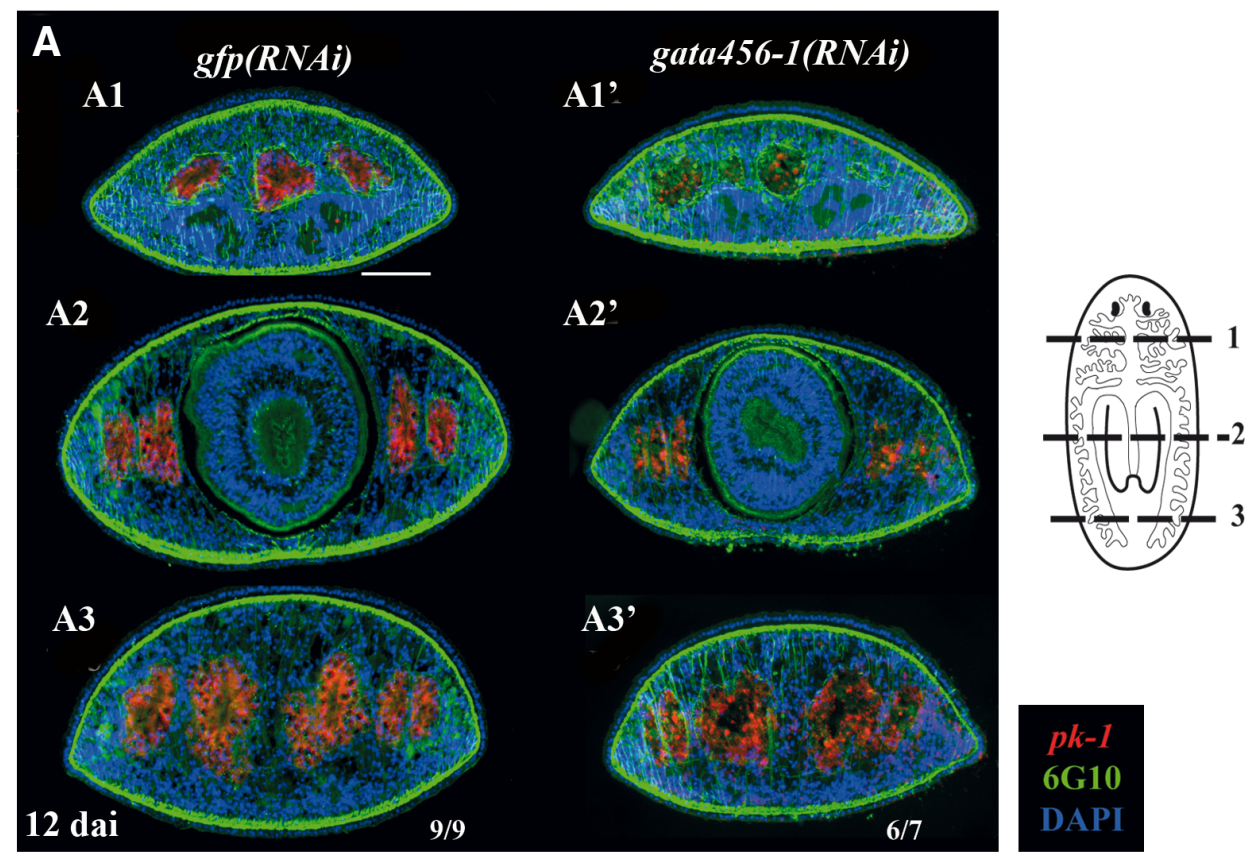

B
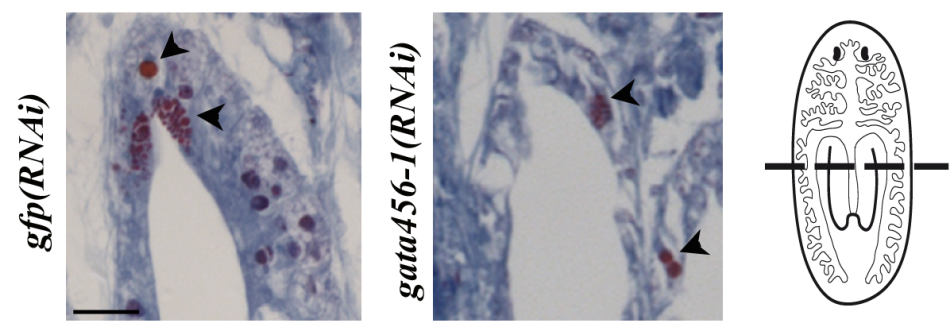

C
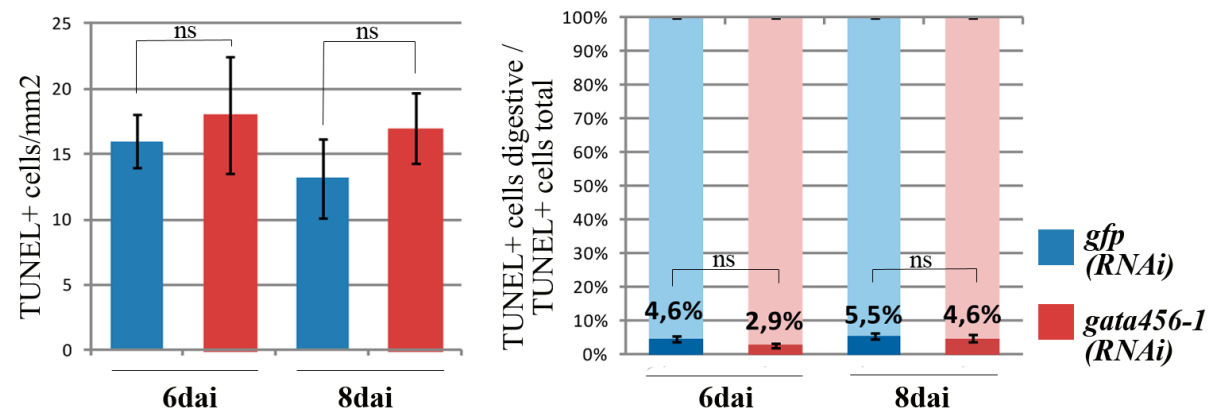

\section{Smed-gata456-1 is necessary for gut remodelling and maintenance}

To better understand the role of Smed-gata456-1 in the gut, we analysed gut remodelling in bilaterally regenerating trunks at 8 days of regeneration and in intact animals using fluorescent in situ hybridization with pk-1 and 6G10 immunohistochemistry. Analysis of regenerating planarians showed no $p k-1$ labelling in the gut of the pharyngeal region, which corresponds to pre-existing tissue (Fig. $2 \mathrm{~A})$. Even though the enteric muscle, as visualized by $6 \mathrm{G} 10 \mathrm{immu}$ nohistochemistry, appeared unaffected (Fig. 2A), the gastrodermis of Smed-gata456-1(RNAi) animals in the pre-existing pharyngeal region was histologically disorganized (Fig. 2A). Disruption of the pre-existing gut was also observed in Mallory-stained sections after Smed-gata456-1(RNAi) (Fig. 2B), in which the gut tissue appears blotted and the brown secretory vesicles characteristic of goblet cells were found dispersed throughout the guttissue (Fig. 2B). The disorganization of gut tissue during planarian regeneration was confirmed by the observed downregulation in Smed-gata456-1(RNAi) animals of Smed-mat (Wagner et al., 2011), a marker of differentiated gut tissue, as determined by qRT-PCR (Fig. 2C), and of Smed-hnf4 (Wagner et al., 2011) and Smed-nkx2.2 (Forsthoefel et al., 2012), both in differentiated and in gut precursor cells (Fig. 2 D-E). These results confirm the destruction of the pre-existing gut in regenerating animals and point to a role of Smed-gata456-1 in gut cell differentiation and survival.

In intact, non-regenerating animals Smed-gata456-1(RNAi) generated lesions and the death of the animals

Fig. 3. Smed-gata456-1(RNAi) impairs gut maintenance during homeostasis. (A) Fluorescent in situ hybridization for pk-1 (red) combined with immunohistochemistry with the 6 G10 antibody (green) in an axial series of transverse sections from intact animals 12 days after the last injection. (B) Mallory staining of transverse sections from intact animals 12 days after the last injection. Arrowheads indicate secretory vesicles of goblet cells. (C) Quantification of TUNEL + cells in intact animals 6 and 8 days after the last dsRNA injection. Left, total number of TUNEL+ cells $/ \mathrm{mm}^{2}$ ( $n=6-7$ sections corresponding to 3 animals at the 6 days time point and $n=13-14$ sections corresponding to 3 animals at the 8 days time point); right, percentage of TUNEL+ cells found in the gastrodermis $\left(n=10-15 \mathrm{sec}^{-}\right.$ tions corresponding to 3 animals at the 6 and 8 days time points). Error bars represent the standard error of the mean; differences are considered significant at $P<0.05$. The dorsal aspect is oriented to the top in $(A, B)$. Scale bars: $100 \mu \mathrm{m}$ in (A); and $10 \mu \mathrm{m}$ in (B). Dashed lines indicate the location of the transverse sections. dai, days after injection. 
between 12 and 16 days after the last dsRNA injection (S. Fig. 7 A-B). Analysis of gut tissue by $p k-1$ in situ hybridization revealed downregulation of pk-1 expression after Smed-gata456-1(RNAi) (Fig. 3 A-A'). This loss of intestinal labelling occurred gradually in an anterior to posterior direction, and was stronger in the anterior (Fig. 3A1') versus the central (Fig. 3A2') and posterior (Fig. 3A3') regions of the animal. Observation of nuclear DAPI staining in those animals demonstrates the gradual loss of gut cells in Smed-gata4561(RNAi)animals (S. Fig. 7C). Mallory staining further demonstrates the disorganization of the gastrodermis in Smed-gata456-1(RNAi) animals 12 days after the last dsRNA injection (Fig. 3B). These results indicate that Smed-gata456-1 is also required for gut cell maintenance during homeostatic tissue renewal.

To check whether the disruption of the gut tissues was caused by the death of pre-existent gut cells, we analyzed the apoptotic levels in Smed-gata456-1(RNAi) animals and their corresponding controls through quantification of caspase-3 enzymatic activity (González-Estévez et al., 2007) and TUNEL(Pelletieri et al., 2010). We analyzed animals 6 and 8 days after the last dsRNA injection, since during this period the gut phenotype is set up (S. Fig. 8A). Our results demonstrate that Smed-gata456-1(RNAi) animals do not show an increase in the total caspase-3 activity or in the number of TUNEL positive cells with respect to the controls (S. Fig. $8 \mathrm{~B}, 3 \mathrm{C})$. Furthermore, our results demonstrate that the percentage of apoptotic cells in the gut compared to the total number of apoptotic cells is maintained in Smed-gata456-1(RNAi) animals with respect to the controls (Fig. $3 \mathrm{C}$ ). Thus, the disappearance of gut cells in Smed-gata456-1(RNAi) planarians is not due to an increase in apoptosis.

Our results suggest that the gut impairment is caused by problems in cell replacement due to improper terminal differentiation of gut cells. However, the early and severe disruption of the gut indicates that Smed-gata456-1 could have a direct role in the maintenance or survival of differentiated gut cells. According to the Mallory staining (Fig. 2B, 3B), gut cells of Smed-gata456-1 (RNAi) animals could be dying through a caspase-independent mechanism as necrosis.

Taken together, these results demonstrate an essential role of Smed-gata456-1 in the regeneration, remodelling, and maintenance of the planarian gut, both in regenerating and in intact animals. The underlying mechanism could be both in blocking terminal differentiation and maintenance of the gut cells.

\section{Tissues other than the gut are not affected in Smed-gata456-1(RNAi) planarians}

To determine whether the effects of Smed-gata456-1 inhibition are gut-specific, we analysed other tissues in Smed-gata4561(RNAi) animals, including the brain, eyes, epidermal precursors, excretory system, and pharynx. Nuclear staining with TOPRO-3 and DAPI revealed normal regeneration of the cephalic ganglia in Smed-gata456-1(RNAi) animals (Fig. 1F, asterisks in Fig. 1G1 and $1 \mathrm{G} 1$ '). This result was confirmed by whole mount fluorescent in situ hybridization and qRT-PCR for the neural marker Smedpc2 (Collins et al., 2010) (Fig. 4A,B). Moreover, normal eye regeneration was observed in in vivo analyses (Fig. 1A), and by double fluorescent in situhybridization with Smed-opsin(SánchezAlvarado and Newmark, 1999), which labels photoreceptor cells, and Smed-tph (Fraguas et al., 2011), which labels pigment cells (Fig. 4C). Quantification of both cell types revealed no difference between Smed-gata456-1(RNAi) animals and controls (Fig. 4D). qRT-PCR of the excretory system marker Smed-CA (Fig. 4E) (Scimone et al., 2011) and the epidermal precursors Smed-prog-1
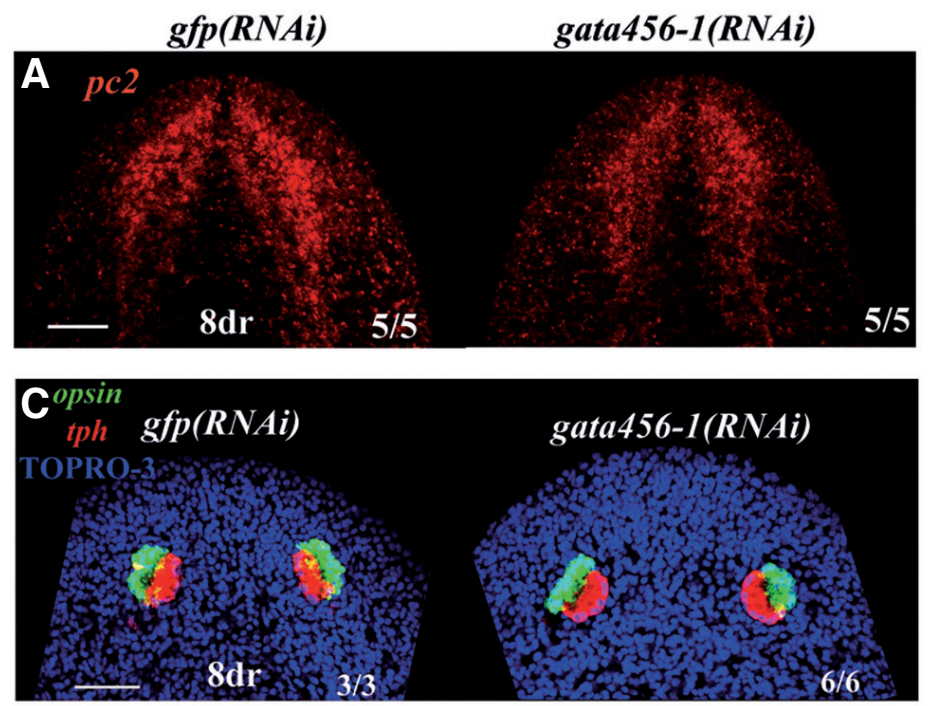

E

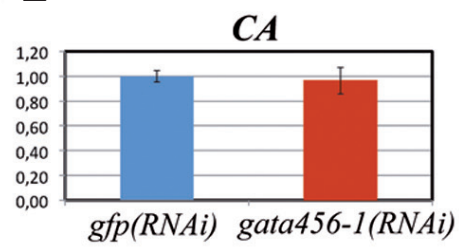

$\mathbf{F}$

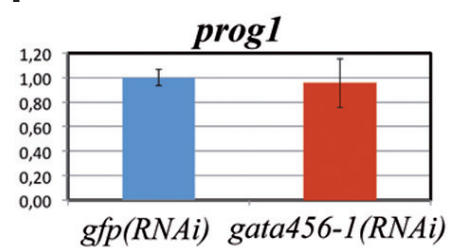

\section{B}
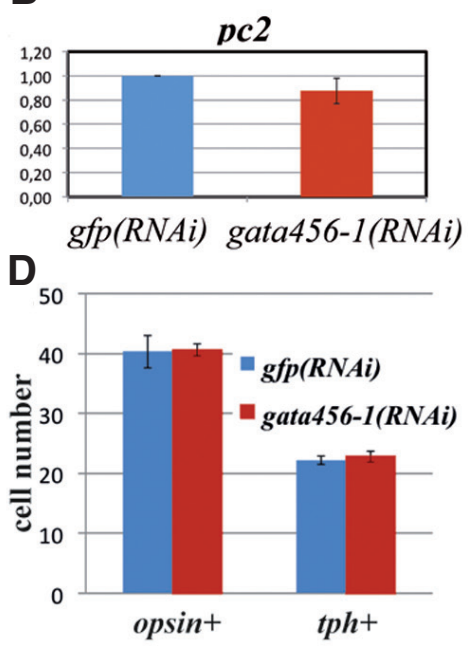

G

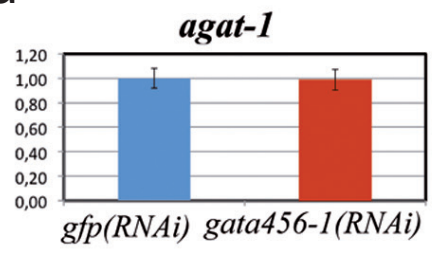

Fig. 4. Non-intestinal tissues are unaffected by Smed-gata4561(RNAi). (A-B) Whole mount fluorescent in situ hybridization (A) and $q R T-P C R$ (B) for the neural marker pc2. (C) Whole mount double fluorescent in situ hybridization for the eye markers opsin (green), a photoreceptor cell marker, and tph (red), a pigment cell marker. (D) Quantification of opsin-positive cells and tph-positive cells (E-F) qRT-PCR of markers of the excretory system (E) and epidermal precursors $(\mathbf{F}, \mathbf{G})$. All experiments were performed on bipolar regenerating trunks after 8 days of regeneration. dr, days of regeneration. Errorbars represent the standard error of the mean. Data were analyzed by Student's $t$-test; differences are considered significant at $P<0.05$. Scale bars: $100 \mathrm{um}$ in (A), 50 um in (C). 
(Fig. 4F) and Smed-agat1 (Fig. 4G) (Eisenhoffer et al., 2008; van Wolfswinkel et al., 2014) also showed no significant differences between Smed-gata456-1(RNAi) animals and controls. Finally, despite the observed disruption of the intestinal tissue, in Smedgata456-1(RNAi) regenerating tails a new pharynx was formed within the pre-existing tissue (Fig. 1F, arrowhead in Fig. 1G4 and 1G4'). Thus, apart from the gut, all tissues analysed (eyes, CNS, excretory system, pharynx, and epidermal lineage) showed normal regeneration following Smed-gata456-1(RNAi), indicating that Smed-gata456-1 is specifically required for gut regeneration and maintenance.

\section{The neoblast population is unaffected by Smed-gata456-1(RNAi)}

Stem cells are one possible source of the defects observed in gut regeneration and maintenance in Smed-gata456-1(RNAi)animals. Alterations in the proliferation of neoblasts or their determination and differentiation into gut cells could contribute to the phenotype observed in these animals. Furthermore, it is possible that these gut defects in turn affect stem cell function (Forsthoefel et al., 2012).

To identify potential neoblast alterations, we analysed expression of the general neoblast markers Smedwi-1 and Smed-h2b (Guo et al., 2006). qRT-PCR of Smedwi-1 revealed no alterations following Smed-gata456-1(RNAi) (Fig. 5A). Moreover, fluorescent in situ hybridization in transverse sections with a Smed-h2b probe revealed a normal distribution of neoblasts, both in the newly re- generated region (Fig. 5 B1-B1'), which lacks a regenerated gut, and in the pre-existing region (Fig. 5 B2-B2'), in which gut branches are remodelled and a new pharynx formed. Thus, neoblasts were distributed in the parenchyma and absent from the gastrodermis. Finally, we investigated whether the lack of neoblast affectation in Smed-gata456-1(RNAi) animals was accompanied by normal proliferation. Immunohistochemistry for phospho-histone H3 (H3P) revealed no significant differences in mitosis with respect to controls (Fig. 5C), neither during early regeneration nor at later stages. Based on these findings, we conclude that Smed-gata456-1(RNAi) has no effect on neoblast number, distribution, or proliferation.

Neoblasts have been described as a heterogeneous population of stem cells, and can be characterized by different attributes such as membrane antigens (Moritz et al., 2012) or their ability to give rise to distinct cell lineages (van Wolfswinkel et al., 2014). The latter study describes two main sub-classes of neoblasts: sigma-neoblasts, which have a broad spectrum of possible fates, and zeta-neoblasts, which are restricted to the epidermal lineage. qRT-PCR of Smed-soxP-2, a sigma-neoblast marker, and of Smedzfp-1, a zeta-neoblast marker, revealed no significant alterations in Smed-gata456-1(RNAi) animals with respect to controls (Fig. 5D and E). Furthermore, analysis of the specific transcription factor Smed-prox-1 to quantify levels of a sub-group of sigma-neoblasts, the gamma-neoblasts, which are defined as gut precursor cells, revealed no differences between Smed-gata456-1(RNAi) animals and controls (Fig. 5F).
A

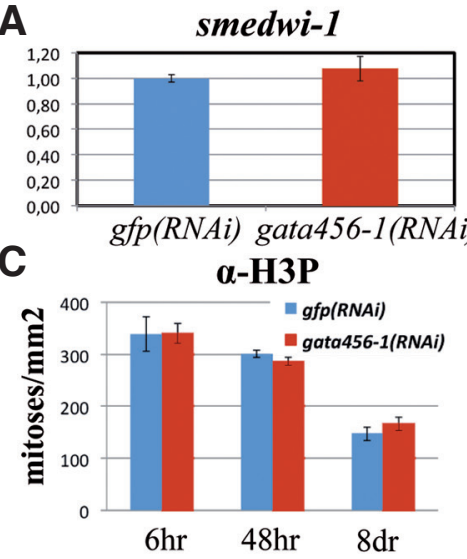

D

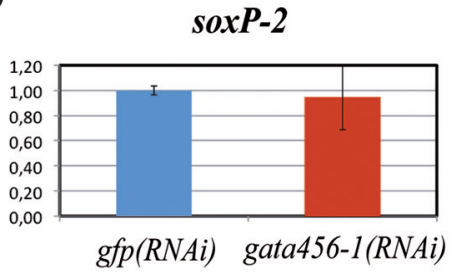

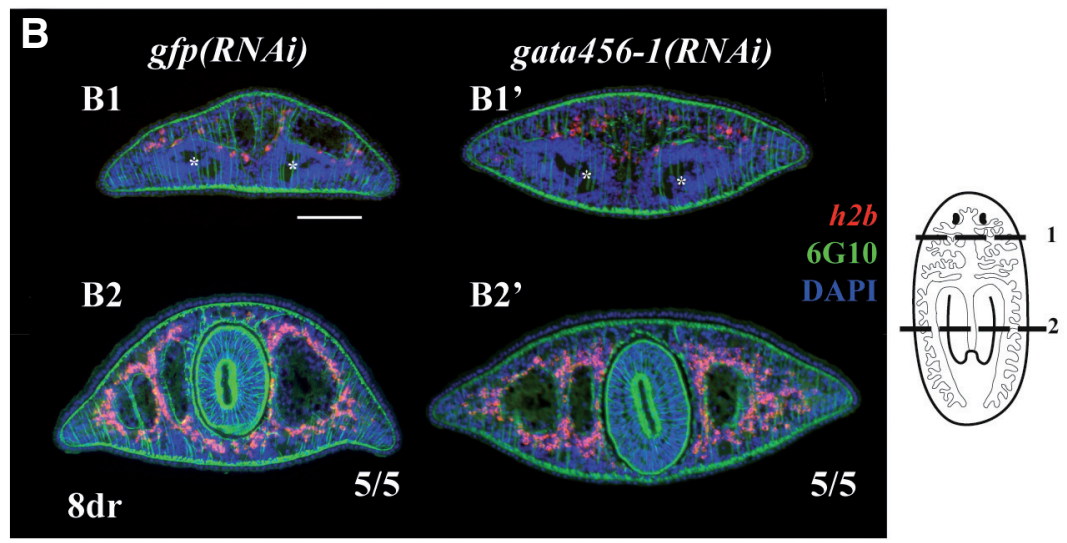

E

$\mathbf{F}$

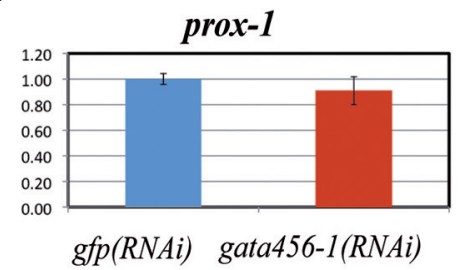

Fig. 5. Normal stem cell distribution and function after Smed-gata456-1(RNAi). (A) qRT-PCR for the neoblast marker smedwi-1. (B) Fluorescent in situ hybridization for the neoblast marker $\mathrm{h} 2 \mathrm{~b}$ (red) combined with immunohistochemistry with the muscle antibody $6 \mathrm{G} 10$ (green) in transverse sections of newly regenerated tissue (B1-B1') and the pre-existing region (B2-B2') of a regenerating tail at 8 days of regeneration. The dorsal aspect is oriented to the top. (C) Quantification of mitotic cells by anti-H3P immunohistochemistry in the whole animal, at different stages of regeneration ( $n=6$ controls and $n=6$ Smed-gata456-1 (RNAi) animals at 6 hours of regeneration; $n=5$ controls and $n=6$ Smed-gata456-1 (RNAi) animals at 48 hours of regeneration; $n=8$ controls and $n=4$ Smed-gata456-1 (RNAi) animals at 8 days of regeneration). (D-F) qRT-PCR for markers of different neoblast classes. Error bars represent the standard error of the mean. Data were analyzed by Student's t-test; differences are considered significant at $P<0.05$. Experiments were performed in bipolar regenerating trunks (A, D-F) and regenerating tails (B) after 8 days of regeneration, and in regenerating tails at different stages of regeneration (C). hr, hours of regeneration; dr, days of regeneration Scale bar: $100 \mu \mathrm{m}$. Dashed lines indicate the location of transverse sections. 
Taken together, these findings indicate that neither inhibition of Smed-gata456-1 nor disruption of the gastrodermis causes any alteration in neoblast number, type, distribution, or proliferation.

\section{Discussion}

\section{Smed-gata456-1 plays an exclusive role in gut cell differentiation and maintenance}

It has been proposed that gut regeneration involves both the differentiation of neoblasts and the migration of differentiated cells from the pre-existing gut to the regenerating zone (Forsthoefel et al., 2011). Thus, in regenerating tails that must regenerate the rest of the animal, the gut near the wound site undergoes significant remodelling and actively contributes to the regeneration of the new gut. In Smed-gata456-1(RNAi) animals the posterior gut branches fused into a single branch in the region anterior to the newly regenerated pharynx. However, no $p k-1$ labelling was observed. This result could indicate a problem during the process of differentiation of new gut cells as well as in the cell fate maintenance of the migrating gut cells. Furthermore, the overall morphology of the presumptive intestinal region, as visualised by immunohistochemistry with the muscle marker 6G10 and the nuclear marker DAPI, also appeared to be altered. This initial remodelling of the gut branches, which fused in the region anterior to the newly regenerated pharynx (Fig. 1G3'), and the subsequent failure in gut elongation, is similar to the phenotype induced by Smed-nkx2.2(RNAi) (Forsthoefel et al., 2012), and may be explained by the contribution of pre-existing tissue to the newly generated tissue. The same mechanism of pre-existing gut cells migration may also explain the faster loss of pk-1 labelling observed in the pharyngeal region of regenerating tails as compared with the posterior tip.

The disruption observed in the gut of Smed-gata456-1(RNAi) animals during homeostasis, as well as the lack of gut remodelling in the pre-existent region of regenerating animals also suggests a role of Smed-gata456-1 in the differentiation of gut cell precursors (gamma-neoblasts) into differentiated gut cells. However, it has been shown that blockade of gut cell differentiation trough Smedegfr-1(RNAi) allows the maintenance of the old gut for several weeks (Barberán et al., 2016). The rapid (8 days after last dsRNA injection in intact animals) and severe disruption of the pre-existing gut following Smed-gata456-1 inhibition suggest that Smedgata456-1 plays an additional role in the maintenance or survival of differentiated gut cells. Quantification of caspase-3 activity and TUNEL staining revealed that apoptosis was not the cause of cell death in Smed-gata456-1(RNAi) animals. The disruption of the gastrodermis revealed by Mallory staining, characterized by soft and swollen tissue with randomly dispersed secretory vesicles of goblet cells, suggests necrotic destruction of gut cells.

The general disruption of the gut observed after Smed-gata4561(RNAi) was accompanied by the appearance of lesions all over the animal between 11 and 15 days after the last injection, both in regenerating and non-regenerating animals (Fig. 1A, Fig. S4 B,D and 7A), followed by death one day later (Fig. 1C, Fig S4 C,E and 7B). In contrast to Smed-nkx2.2(RNAi) animals (Forsthoefel et al., 2012), the lesions observed affected the entire body and not just the region over the gut. It is possible that disruption of the gut triggers the rupture of digestive vesicles, provoking the digestion of planarian tissues, which gives rise to the observed lesions and ultimately leads to death. That markers of epidermal cell lineages
(Smed-prog-1, Smed-agat-1) were unaltered in Smed-gata4561(RNAi) animals supports the view that these lesions are caused not by the impairment of epidermal differentiation but rather by a direct mechanism such as ectopic digestion. Furthermore, the decrease in caspase-3 activity observed in Smed-gata456-1(RNAi) intact animals 8 days after the last dsRNA injection, indicates that lesions are not produced by a caspase-3 dependent mechanism as programmed cell death.

Although the gut disruption and the lesions were observed throughout the body of Smed-gata456-1(RNAi) animals, a graded affectation along the antero-posterior axis was evident in both regenerating and intact animals. Thus, lesions were more prevalent in the anterior portion, and intestinal $p k-1$ labelling was weaker in the anterior region of non-regenerating animals. This graded affectation is also observed following inhibition of other genes involved in gut regeneration. For example, Smed-nkx2.2(RNAi) results in partial depletion of neoblasts exclusively in the anterior portion (Forsthoefel et al., 2012), while the reduction in size and number of secondary, tertiary, and quaternary gut branches observed after Smed-egfr-1 (RNAi) is more severe in the anterior region (Barberán et al., 2016). This phenomenon may be in part attributable to the physiological gradient theory, that proposes a quantitative difference in metabolic activity along the A-P axis (Child, 1929; Blackstone, 2006), as suggested by the higher cell turnover in anterior-most regions (Eisenhoffer et al., 2008).

Overall, our results suggest a role of Smed-gata456-1 in the differentiation and maintenance of gut cells in Schmidtea mediterranea. This dual function is also observed in other models such as Drosophila melanogaster, in which dGATAe is required for late differentiation and to maintain the correct shape and expression profile of adult enterocytes (Murakami et al., 2005; Buchon et al., 2013). The expansion of the gata456 family (Gillis et al., 2008; Tang et al., 2014) leaves open the possibility that different members of this family have other gut-related functions, such as early determination of gut cells. In D. melanogaster another member of the family, srp/dGATAb, acts as a selector gene in endoderm determination (Reuter, 1994), while in Caenorhabditis elegans end-2 is necessary for the early determination of the endoderm (Zhu et al., 1997) and elt-2 is essential for terminal differentiation of the gut (Fukushige et al., 1998). However, although further experiments are required, the second member of the gata 456 family found in planarians (Smed-gata456-2) does not appear to have any direct function in gut tissues.

Despite the severe affliction of the gut in Smed-gata456-1(RNAi) animals, none of the other tissues analysed in the present study, including the nervous system, excretory system, and the eyes, showed any alterations. This was particularly obvious in regenerating Smed-gata456-1(RNAi) tails, in which the brain and even the pharynx were regenerated de novo in animals that failed to regenerate the anterior gut branch (Fig. $1 \mathrm{E}-\mathrm{F}$ ). Quantification of specific non-gut-related markers further demonstrated that structures other that the gut were unaffected. This observation contradicts a recent study (Flores et al., 2016) in which Smed-gata456-1 silencing resulted in similar disruption of gut regeneration and maintenance, accompanied by lesions and death of the animal, but also caused defects in the regeneration of the nervous system and eyes. One potential explanation for these conflicting findings is the different protocols used for RNAi; Flores and coworkers used dsRNA feeding, which is less effective than injection and produces 
general and sustained activation of proliferation due to food ingestion. This effect is evident in the longer survival time, measured from the first day of RNAi treatment, reported by Flores et al., The timing of the experiment should be also considered; our experiments involved a 7-day interval between the first dsRNA injection and amputation, as compared with the 11-day interval used by Flores et al., The milder and longer RNAi treatment used by Flores et al., may thus have resulted in earlier, but less apparent gut disruption, ultimately causing general disruption of the different cell compartments and tissues that could be observed before death. In our experiments, the rapid tissue deterioration observed in the gut was not observed in any other of the other tissues analysed, which showed normal early regenerative behaviour.

\section{The lack of neoblast affectation following Smed-gata456-1(RNAi) questions the existence of a gut neoblast niche}

Previous findings demonstrating an increase in proliferation shortly after feeding (Baguñà, 1976,) suggest that this rapid response may be mediated by close communication between intestinal cells and neoblasts. Thus, the planarian gut may act as a neoblast "niche", sending proliferation, differentiation, or self-renewal signals to neoblasts. Forsthoefel and coworkers reported that inhibition of Smed-nkx2.2 decreases proliferation after affecting the gut (Forsthoefel et al., 2012). However, those authors proposed that this decrease in proliferation may involve elements downstream of the inhibited gene, rather than the gut itself. By contrast, Barberán and coworkers show that inhibition of Smed-egfr-1, which blocks the differentiation of new gut cells and leads to progressive decay of the gut, results in neoblast accumulation and increased proliferation (Barberán et al., 2016). Although these two findings appear contradictory, both are in agreement with the proposed close correlation between neoblasts and the gut. In our experiments, we observed no alterations in the stem cell compartment in Smed-gata456-1(RNAi) animals, in which the gut compartment appears to be specifically affected, and no defects in neoblast distribution nor proliferation were observed. Furthermore, these animals displayed no alterations in the different neoblast subpopulations. In the case of gamma-neoblasts, although prox-1 levels were normal, qRT-PCR for the markers Smed-hnf4 and Smed-nkx2.2 revealed clear downregulation following Smed-gata456-1(RNAi). Given that prox-1 is specifically expressed in gamma neoblasts, and Smed-hnf4 and Smed-nkx2.2 are expressed in both gamma neoblasts and in differentiated gut cells (Wurtzel et al., 2015), the observed downregulation of Smedhnf4 and Smed-nkx2.2 may be a result of the defects observed in the gut itself. Although Smed-gata456-1 is expressed in gamma neoblasts (van Wolfswinkel et al., 2014), it may only be required for the differentiation of these cells to intestinal cells, but not for their maintenance. It is also possible that Smed-gata456-1 inhibition affects communication between the two compartments, and hence that stem cells do not sense the disruption of the gut. In contrast to our results, Flores and colleagues reported that Smed-gata456-1 inhibition causes downregulation of all neoblast types, particularly gamma-neoblasts. The same argument proposed above for the differences observed regarding central nervous system and eye regeneration may explain the apparent disparity between the two studies. The dsRNA injection used in the present study compared to the dsRNA feeding used by Flores et al., produces a rapid and severe gut deterioration that leaves no time to be sensed by the other compartments. Moreover, the RNAi carried out by injection does not produce a sustained increase in proliferation like the one by feeding, which could as well produce a different response of the neoblast. Thus, neoblast affectation observed in Flores et al., may be explained by an indirect effect due to the experimental procedure. Our findings suggest that the primary role of Smedgata456-1 is in gut cell differentiation and maintenance.

\section{Conclusion}

In summary, we demonstrate that in Schmidtea mediterranea the pioneer factor Smed-gata456-1 has a specific and evolutionarily conserved role in endoderm differentiation and maintenance, while Smed-gata456-2 is involved in the establishment of anterior mediolateral patterning during regeneration. Smed-gata456-1 is 
required for gut cell differentiation from gamma neoblasts and for the maintenance or survival of differentiated gut cells (summarized in Fig. 6), and is thus essential for gut regeneration and maintenance. Smed-gata456-1 (RNAi)results in severe and specific affectation of the gut, ultimately resulting in death, with no effects on the neoblast compartment, even the gamma neoblast subpopulation. These findings suggest that in planarians gata $456-1$ is not involved in the early specification of neoblasts to gut precursors. Furthermore, the gut-specific function of Smed-gata456-1 is confirmed by the lack of affectation of other tissues in Smed-gata456-1(RNAi) animals. Taken together, our results call into question the proposed existence of a gut neoblast niche.

\section{Materials and Methods}

\section{Organisms}

The planarians used in this study belong to an asexual biotype of Schmidtea mediterranea (asexual $\mathrm{BCN}-10$ clonal line). Animals were maintained at $20^{\circ} \mathrm{C}$ in artificial water (Cebrià and Newmark, 2005), fed with organic veal liver, and starved for at least one week before experiments.

\section{Molecular phylogenetic analysis}

Conserved dual zinc-finger domains of GATA sequences from different species were aligned using the MAFFT server (http://mafft.cbrc.jp/alignment/ server/). Neighbour-joining distance-based analyses were conducted using MEGA version 6 (Tamura et al., 2013), and the support given by bootstrap percentiles of 1000 replicates.

\section{RNAi analysis}

Double-stranded RNA (dsRNA) for Smed-gata456-1 (JF802198) and Smed-gata456-2 (KX827244) was synthesized by in vitro transcription (Roche), as described previously (Sánchez Alvarado and Newmark, 1999), with a length of 469 and 419 bp, respectively. dsRNA microinjections were performed as described previously (Sánchez Alvarado and Newmark, 1999), following the standard protocol of 3 injections of $32 \mathrm{nl}$ of dsRNA at a concentration of $1000 \mathrm{ng} / \mu \mathrm{l}$, on 3 consecutive days. Control animals were injected with dsRNA corresponding to GFP, a gene not found in the genome of $S$. mediterranea. For regeneration experiments, Smed-gata456-1(RNAi) animals were amputated pre- and postpharyngeally 4 days after the last injection and allowed to regenerate. Successful RNAi was confirmed by qRT-PCR. In Smed-gata456-2(RNAi) experiments, animals received one round of injections on 3 consecutive days, followed by amputation on the day 4 , and a second round beginning 4 days after amputation.

\section{Irradiation}

Intact planarians were X-irradiated at 96 Gy (1.6 Gy/minute) with a X ray cabinet Maxi Shot 200 (Ylon Int.) at the facilities of the Scientific and Technological Center of the University of Barcelona (CCiTUB). One day after irradiation they were processed as explained in the whole mount in situ hybridization protocol.

\section{Quantitative real-time PCR}

Quantitative real-time PCR experiments were performed as described previously (Solana et al., 2012). All experiments were performed using 3 biological and 3 technical replicates, using a pool of 5 animals for each biological replicate. The animals used for analysis were trunk regenerating fragments at 8 days of regeneration with no wounds. Results were normalized with respect to the ura4 gene. The following primers were used $\left(5^{\prime} \rightarrow 3^{\prime}\right)$ : agat1-1F, TCCATCCAGAACCGATTGAT; agat1-1R, CTCCCAAGTCATGGTGGACT; gata456-1-1F, TGATCCCTGGAGCTGTAAA; gata456-1-1R, TTGCTAGCTCCACAGTTCAC; hnf4-1F,ACAAGCTATCAATCTCGGCT; hnf41R, GCTGCTGACAATTCCTGA; mat-1F, GACCTGGCCACATAGAAAA; mat-1R, CCATGTAAACTCTGGTCTTCC; nkx2.2-1F, ATTCAGCG-
TACGGATCACT; nkx2.2-1R, TTCCATTGATATCGGGGT; pc2-1F, ACGATTTCACTGCATTGC; pc2-1R, TATCTGATTTGCACGCGT; prog1-1F, TCCGTTTTTCACGTCATCTG; prog1-1R, TTGCGTTCGCGTATATTGAA; prox-1-1F, CCATCAAACAGTTCCCAGT; prox-1-1R, GTTTGGCCTTTCGTAAATG; smedwi-1-1F, GATGGGGCTAATCCAAATCC; smedwi-1-1R, AATTCGTAGGAGATGCTGTACC; soxp2-1F, CCAGCAATTTTCCCAAAG; soxp2-1R, CCCCTTCTGAATCATCCAT; ura4-1F, TTCACGTTGTCGATCTAGCC; ura4-1R, CGAATATCCTCTGCCAGTGC; zfp1-1F, AAATTTTCCCGTGCCTG; zfp1-1R, TGATCTTTGAGTGAAGCTGGT.

\section{Whole-mount immunohistochemistry}

Immunostaining was carried out as described previously (Ross et al., 2015). Animals were sacrificed in $2 \% \mathrm{HCl}$ in milli-Q water and fixed in $4 \%$ formaldehyde in PBS $/ 0.3 \%$ Triton. The following primary antibodies were used: $\alpha$-phospho-histone H3 (H3P), to detect mitotic cells (1:500; Cell Signaling Technology); $\alpha$-arrestin (VC-1), to detect planarian photoreceptor cells (1:15000; Sakai et al., 2000, kindly provided by Dr. Hidefumi Orii and Prof. Kenji Watanabe); and $\alpha$-SYNORF-1, to detect the pan-neural marker synapsin (1:20; Developmental Studies Hybridoma Bank). The secondary antibodies used wereAlexa 568-conjugated goat $\alpha$-rabbit (1:1000; Molecular Probes) and Alexa 488-conjugated goat $\alpha$-mouse (1:400; Molecular Probes)

\section{Whole-mount In situ hybridization}

Colorimetric whole mount in situ hybridization was performed using an In situ Pro hybridization robot (Abimed/Intavis) as previously described (Molina et al., 2007). Fluorescent whole mount in situ hybridization was performed manually as previously described (King and Newmark 2013).

\section{Immunohistochemistry, in situ hybridization, Mallory staining and TUNEL assay on paraffin sections}

In situ hybridization combined with immunohistochemistry using paraffin sections was performed as described previously (Barberán et al., 2016). Mallory staining was performed as previously described (Sluys 1989). TUNEL staining was performed in paraffin sections as described previously (Almuedo-Castillo et al., 2014) and following manufacturer's recommendations (ApopTag Red In situ Apoptosis Detection Kit, Merck-Millipore).

\section{Imaging}

Colorimetric whole mount in situ hybridization samples were observed through a Leica MS16F stereomicroscope and images captured with a Jenoptik ProgRes C3 camera. FISH images were obtained by confocal laser scanning microscopy using a Leica SPE confocal microscope. Sections were imaged using a Zeiss Axiophot microscope with a Leica DFC300FX camera for Mallory staining and a Jenoptik ProgRes MF camera for fluorescent images. Images were processed using Fiji and Photoshop CS3 (Adobe) software.

\section{Analysis of caspase-3 activity}

Quantification of caspase-3 activity was performed as described previously (González-Estévez et al., 2007).

\section{Data availability}

The sequence of Smed-gata456-2 has been deposited in GenBank with accession number KX827244.

Genbank accession numbers

Smed-gata456-2 KX827244.

\section{Competing interests}

The authors declare no competing of financial interests.

\section{Authors' contributions}

AGS and ES conceived and designed the study. AGS conducted most of the experiments. NDS and TA carried out the cell death and the phylogenetic analysis, respectively. AGS drafted the manuscript with contributions from 
all authors. TA and ES edited the paper. All authors read and approved the final manuscript.

\section{Acknowledgements}

We would like to thank all members of the Saló and Cebrià labs for their support and discussion, Dr. Francesc Cebrià and Dr. lain Patten for editorial advice, Dr. Owen Howard for English language editing, and Dr. Hidefumi Orii and Prof. Kenji Watanabe for the VC-1 antibody.

\section{Funding}

This work was supported by grants BFU2011-22786 and BFU201456055P from the Ministerio de Economía y Competitividad, Spain (to ES), and grants 2009SGR1018 and 2014SGR-2016 from the Agència de Gestió d'Ajuts Universitaris i de Recerca (to ES). AGS is a recipient of a FPU fellowship from the MECD, Spain, and NDS is a recipient of a APIF fellowship from the Universitat de Barcelona.

\section{References}

ALMUEDO-CASTILLO M, CRESPO-YANEZ X, SEEBECK F, BARTSCHERER K, SALÓ E, ADELL T. (2014). JNK controls the onset of mitosis in planarian stem cells and triggers apoptotic cell death required for regeneration and remodeling. PLoS Genet 10:e1004400.

BAGUÑ̀̀, J. (1976). Mitosis in the intact and regenerating planarian Dugesia mediterranea $\mathrm{n} . \mathrm{sp}$. I. Mitotic studies during growth, feeding and starvation. J Exp Zool 195: 53-64.

BAGUÑ̇̀, J. (2012). The planarian neoblast: the rambling history of its origin and some current black boxes. Int J Dev Biol 56(1-3): 19-37.

BARBERÁN, S., FRAGUAS, S. and CEBRIÀ, F. (2016). The EGFR signaling pathway controls gut progenitor differentiation during planarian regeneration and homeostasis. Development 143: 2089-2102.

BEULING, E., ARONSON, B. E., TRAN, L. M. D., STAPLETON, K. A., HORST, TER, E. N., VISSERS, L. A. T. M., et al., (2012). GATA6 is required for proliferation, migration, secretory cell maturation, and gene expression in the mature mouse colon. Mol Cell Biol 32: 3392-3402.

BLACKSTONE, NEIL W. (2006). Charles Manning Child (1869-1954): The Past, Present, and Future of Metabolic Signaling. J Exp Zool (Mol Dev Evol)306B: 1-7 (2006)

BRANDL, H., MOON, H., VILA-FARRÉ, M., LIU, S.-Y., HENRY, I. and RINK, J. C. (2015). PlanMine - a mineable resource of planarian biology and biodiversity. Nucl Acids Res 44(D1): D764-773

BUCHON, N., OSMAN, D., DAVID, F.P.A., FANG, H. Y., BOQUETE, J.-P., DEPLANCKE, B. and LEMAITRE, B. (2013). Morphological and molecular characterization of adult midgut compartmentalization in Drosophila. Cell Reports 3: 1725-1738.

CEBRIÀ, F. and NEWMARK, P. A. (2005). Planarian homologs of netrin and netrin receptor are required for proper regeneration of the central nervous system and the maintenance of nervous system architecture. J Embryol Exp Morphol 132: 3691-3703.

COLLINS, J. J., HOU, X., ROMANOVA, E. V., LAMBRUS, B. G., MILLER, C. M., SABERI, A., et al. (2010). Genome-wide analyses reveal a role for peptide hormones in planarian germline development. PLoS Biol 8(10), e1000509.

CHILD C.M. (1929). The physiological gradients. Protoplasma 5: 447-476

EISENHOFFER, G. T., KANG, H. and SÁNCHEZ ALVARADO, A. (2008). Molecular analysis of stem cells and their descendants during cell turnover and regeneration in the planarian Schmidtea mediterranea. Cell Stem Cell 3: 327-339.

FLORES, N. M., OVIEDO, N. J., SAGE, J. (2016). Essential role for the planarian intestinal gata transcription factor in stem cells and regeneration. Dev Biol 418:179-188. http://dx.doi.org/10.1016/j.ydbio.2016.08.015

FORSTHOEFEL, D. J., PARK, A. E. and NEWMARK, P. A. (2011). Stem cell-based growth, regeneration, and remodeling of the planarian intestine. Dev Biol 356: 445-459.

FORSTHOEFEL, D. J., JAMES, N. P., ESCOBAR, D. J., STARY, J. M., VIEIRA, A. P., WATERS, F. A. and NEWMARK, P. A. (2012). An RNAi screen reveals intestinal regulators of branching morphogenesis, differentiation, and stem cell proliferation in planarians. Dev Cell 23: 691-704.

FRAGUAS, S., BARBERÁN, S. and CEBRIÀ, F. (2011). EGFR signaling regulates cell proliferation, differentiation and morphogenesis during planarian regeneration and homeostasis. Dev Biol 354(1), 87-101.

FRAGUAS, S., BARBERÁN, S., IGLESIAS, M., RODRÍGUEZ-ESTEBAN, G. and CEBRIÀ, F. (2014). egr-4, a target of EGFR signaling, is required for the formation of the brain primordia and head regeneration in planarians. Development 141: 1835-1847.

FUKUSHIGE, T., HAWKINS, M. G. and MCGHEE, J. D. (1998). The GATA-factor elt-2 is essential for formation of the Caenorhabditis elegans intestine. Dev Biol 198: 286-302.

GARCIA-CORRALES, P. and GAMO, J. (1986). The ultrastructure of the gastrodermal gland cells in the freshwater planarian Dugesiagonocephalas.l. ActaZool67:43-51.

GILLIS, W. Q., BOWERMAN, B. A. and SCHNEIDER, S. Q. (2008). The evolution of protostome GATA factors: molecular phylogenetics, synteny, and intron/exon structure reveal orthologous relationships. BMC Evol Biol 8: 112.

GONZALEZ-ESTEVEZ, C., FELIX, D. A., ABOOBAKER, A. A. and SALÓ, E. (2007). Gtdap-1 promotes autophagy and is required for planarian remodeling during regeneration and starvation. Proc Natl Acad Sci USA 104: 13373-13378.

GUO, T., PETERS, A. H. F. M. and NEWMARK, P. A. (2006). A Bruno-like gene is required for stem cell maintenance in planarians. Dev Cell 11: 159-169.

KING, R. S. and NEWMARK, P. A. (2013). In situ hybridization protocol for enhanced detection of gene expression in the planarian Schmidtea mediterranea. BMC Dev Biol 13: 8.

MARTíN-DURÁN, J. M. and ROMERO, R. (2011). Evolutionary implications of morphogenesis and molecular patterning of the blind gut in the planarian Schmidtea polychroa. Dev Biol, 352: 164-176.

MOLINA, M. D., SALÓ, E. and CEBRIÀ, F. (2007). The BMP pathway is essential for re-specification and maintenance of the dorsoventral axis in regenerating and intact planarians. Dev Biol 311: 79-94.

MORITZ, S., STÖCKLE, F., ORTMEIER, C., SCHMITZ, H., RODRÍGUEZ-ESTEBAN, G., KEY, G. and GENTILE, L. (2012). Heterogeneity of planarian stem cells in the S/G2/M phase. Int J Dev Biol 56(1-2-3): 117-125.

MURAKAMI, R., OKUMURA, T. and UCHIYAMA, H. (2005). GATA factors as key regulatory molecules in the development of Drosophila endoderm. Dev Growth Differ 47: 581-589.

OKUMURA, T., TAKEDA, K., KUCHIKI, M., AKAISHI, M., TANIGUCHI, K. and ADACHI-YAMADA, T. (2016). GATAe regulates intestinal stem cell maintenance and differentiation in Drosophila adult midgut. Dev Biol 410: 24-35.

PELLetTIERI, J., FItZGERALD, P., WATANABE, S., MANCUSO, J., GREEN, D. R. and SÁNCHEZ ALVARADO, A. (2010). Cell death and tissue remodeling in planarian regeneration. Dev Biol. 338: 76-85.

REITER, J. F., KIKUCHI, Y. and STAINIER, D. Y. (2001). Multiple roles for Gata5 in zebrafish endoderm formation. Development 128: 125-135.

REUTER, R. (1994). The gene serpent has homeotic properties and specifies endoderm versus ectoderm within the Drosophila gut. J Embryol Exp Morphol 120: 1123-1135.

ROSS, K. G., OMURO, K. C., TAYLOR, M. R., MUNDAY, R. K., HUBERT, A., KING, R. S. and ZAYAS, R. M. (2015). Novel monoclonal antibodies to study tissue regeneration in planarians. BMC Dev Biol 15: 2.

SAKAI, F., AGATA, K., ORII, H. and WATANABE, K. (2000). Organization and regeneration ability of spontaneous supernumerary eyes in planarians -eye regeneration field and pathway selection by optic nerves-. Zool Sci 17: 375-381.

SALÓ, E. (2006). The power of regeneration and the stem-cell kingdom: freshwater planarians (Platyhelminthes). BioEssays 28: 546-559.

SÁNCHEZ ALVARADO, A. and NEWMARK, P. A. (1999). Double-stranded RNA specifically disrupts gene expression during planarian regeneration. Proc Natl Acad Sci USA 96: 5049-5054.

SCIMONE, M. L., SRIVASTAVA, M., BELL, G. W. and REDDIEN, P. W. (2011). A regulatory program for excretory system regeneration in planarians. Development 138: 4387-4398.

SLUYS, R., 1989. A Monograph of the Marine Triclads. A. A. Balkema, Rotterdam \& Brookfield, Rotterdam.

SOLANA, J., KAO, D., MIHAYLOVA, Y., JABER-HIJAZI, F., MALLA, S., WILSON, R. and ABOOBAKER, A. A. (2012). Defining the molecular profile of planarian pluripotent stem cells using a combinatorial RNAseq, RNA interference and irradiation approach. Genome Biol 13: R19. 
TAMURAK, STECHER G, PETERSON D, FILIPSKIA and KUMAR S (2013) MEGA6: Molecular Evolutionary GeneticsAnalysis version 6.0. MolBiol Evol30:2725-2729.

TANG, Y., WEI, Y., HE, W., WANG, Y., ZHONG, J. and QIN, C. (2014). GATA transcription factors in vertebrates: evolutionary, structural and functional interplay. Mol Genet Genomics 289: 203-214.

VAN WOLFSWINKEL, J. C., WAGNER, D. E. and REDDIEN, P. W. (2014). Singlecell analysis reveals functionally distinct classes within the planarian stem cell compartment. Cell Stem Cell 15: 326-339.

WAGNER, D. E., WANG, I. E. and REDDIEN, P. W. (2011). Clonogenic neoblasts are pluripotent adult stem cells that underlie planarian regeneration. Science
332: 811-816.

WURTZEL, O., COTE, L. E., POIRIER, A., SATIJA, R., REGEV, A. and REDDIEN, P. W. (2015). A Generic and Cell-Type-Specific Wound Response Precedes Regeneration in Planarians. Dev Cell, 35: 632-645.

ZARET, K. S. and CARROLL, J. S. (2011). Pioneer transcription factors: establishing competence for gene expression. Genes Dev 25: 2227-2241.

ZHU, J., HILL, R. J., HEID, P. J., FUKUYAMA, M., SUGIMOTO, A., PRIESS, J. R. and ROTHMAN, J. H. (1997). end-1 encodes an apparent GATA factor that specifies the endoderm precursor in Caenorhabditis elegans embryos. Genes Dev 11: 2883-2896. 


\section{Further Related Reading, published previously in the Int. J. Dev. Biol.}

Regeneration in spiralians: evolutionary patterns and developmental processes

Alexandra E. Bely, Eduardo E. Zattara and James M. Sikes

Int. J. Dev. Biol. (2014) 58: 623-634

https://doi.org/10.1387/ijdb.140142ab

Characterization of proteolytic activities during intestinal regeneration of the sea cucumber, Holothuria glaberrima Consuelo Pasten, Rey Rosa, Stephanie Ortiz, Sebastián González and José E. García-Arrarás Int. J. Dev. Biol. 56: 681 - 691 (2012)

https://doi.org/10.1387/ijdb.113473cp

Planarian regeneration: a classic topic claiming new attention

Emili Saló and Kiyokazu Agata

Int. J. Dev. Biol. (2012) 56: 1-4

https://doi.org/10.1387/ijdb.123495es

The planarian neoblast: the rambling history of its origin and some current black boxes Jaume Baguñà

Int. J. Dev. Biol. (2012) 56: 19-37

https://doi.org/10.1387/ijdb.113463jb

Planarian regeneration: achievements and future directions after 20 years of research Emili Saló, Josep F. Abril, Teresa Adell, Francesc Cebriá, Kay Eckelt, Enrique FernándezTaboada, Mette Handberg-Thorsager, Marta Iglesias, M Dolores Molina and Gustavo Rodríguez-Esteban

Int. J. Dev. Biol. (2009) 53: 1317-1327

https://doi.org/10.1387/ijdb.072414es

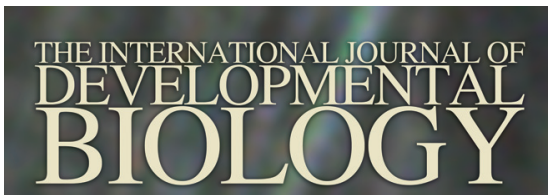

Volume 56 Nos. 1/2/3

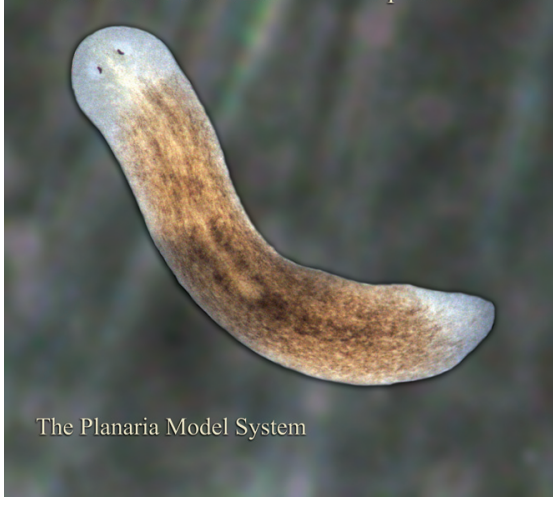

5 yr ISI Impact Factor $(2013)=2.879$

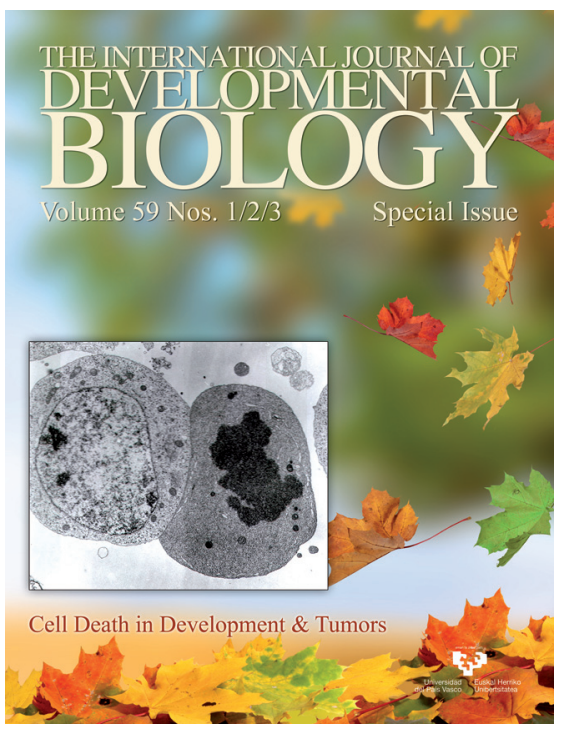

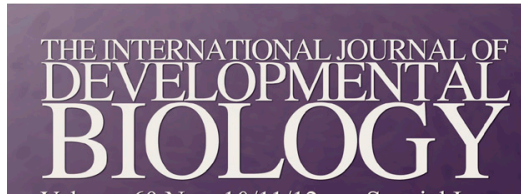

Volume 60 Nos. 10/11/12

Special Issue
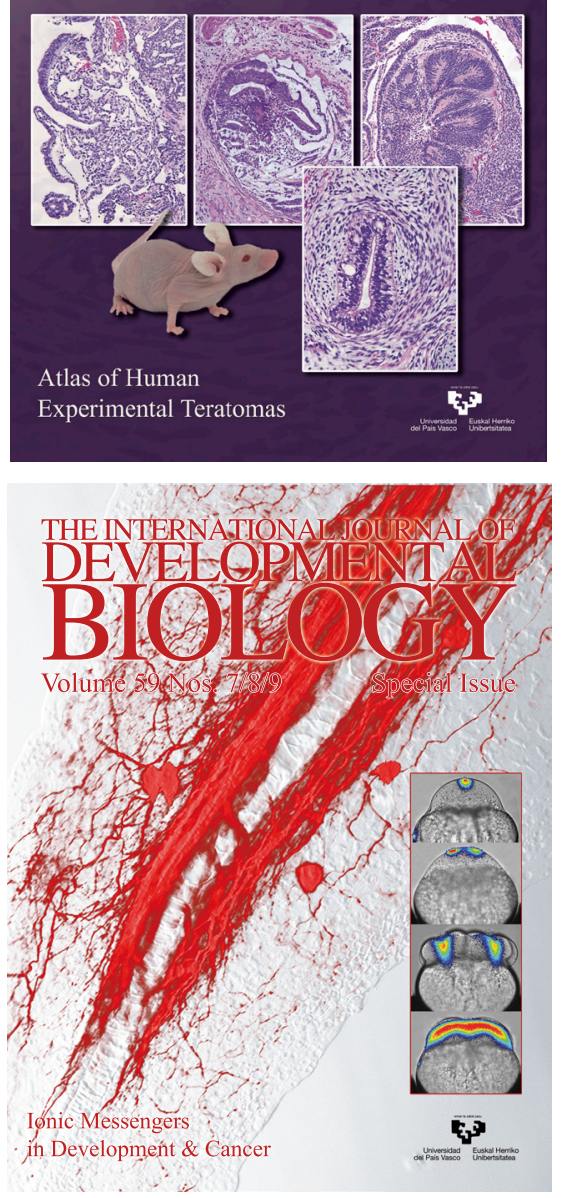